\title{
Article \\ The Use of Hirshfeld Surface Analysis Tools to Study the Intermolecular Interactions in Single Molecule Magnets
}

\author{
Vassilis Psycharis*D, Despina Dermitzaki and Catherine P. Raptopoulou \\ Institute of Nanoscience and Nanotechnology, National Center for Scientific Research "Demokritos", \\ 15310 Athens, Greece; d.dermitzaki@inn.demokritos.gr (D.D.); c.raptopoulou@inn.demokritos.gr (C.P.R.) \\ * Correspondence: v.psycharis@inn.demokritos.gr; Tel.: +30-210-6503346
}

check for updates

Citation: Psycharis, V.; Dermitzaki,

D.; Raptopoulou, C.P. The Use of

Hirshfeld Surface Analysis Tools to Study the Intermolecular Interactions in Single Molecule Magnets. Crystals 2021, 11, 1246. https://doi.org/ $10.3390 /$ cryst11101246

Academic Editor: Arcady Zhukov

Received: 15 September 2021

Accepted: 10 October 2021

Published: 14 October 2021

Publisher's Note: MDPI stays neutral with regard to jurisdictional claims in published maps and institutional affiliations.

Copyright: (c) 2021 by the authors. Licensee MDPI, Basel, Switzerland. This article is an open access article distributed under the terms and conditions of the Creative Commons Attribution (CC BY) license (https:// creativecommons.org/licenses/by/ $4.0 /)$

\begin{abstract}
Intermolecular interactions have proved to play an important role in properties of SMMs such as quantum tunneling of magnetization (QTM), and they also reduce the rate of magnetic relaxation, as through the influence they have on QTM, they quicken the reverse of magnetization. In addition, they are considered as the generative cause of the exchange-biased phenomenon. Using the Hirshfeld analysis tools, all the intermolecular interactions of a molecule and its neighbors are revealed, and this leads to a systematic study of the observed interactions, which could probably be helpful in other studies, such as theoretical calculations. In addition, they could be helpful to design new systems because intermolecular interactions in SMMs have been proposed as a probable tool to monitor their properties. The observation of characteristic patterns on the Hirshfeld Surfaces (HS) decorated with different properties makes easier the recognition of possible structural pathways for the different types of interactions of a molecule with its surrounding.
\end{abstract}

Keywords: single molecule magnets; Hirshfeld surface; hydrogen bonds; $\pi \cdots \pi$ interactions

\section{Introduction}

The advent of single molecule magnets (SMMs) opened a new field in the synthesis of molecular materials, because the bottom-up approach used in their synthesis gives great chemical flexibility with the use of different ligands for tailoring their magnetic properties. The magnetic properties of SMMs have been studied extensively and a large number of complexes have been produced, presenting the characteristic properties of these compounds, i.e., slow magnetic relaxation of magnetization below a blocking temperature, quantum tunneling of magnetization (QTM), etc. [1,2]. The characteristic SMMs properties are revealed by studying them on single crystals or on oriented powders, because in the solid state they are a collection of identical oriented nanomagnets and their large number, i.e., with the order of magnitude of Avogadro's number, makes possible the observation of quantum properties of a single molecule, on a macroscopic scale [3,4]. The magnetic properties of SMMs originate from the properties of each molecule and not from long-range ordering phenomena within the crystal lattice [5]. The intermolecular interactions between neighboring SMMs in the crystal lattice influence the magnetic and quantum properties of each molecule, and their presence has characterized a new family of SMMs, the so-called exchange-biased one. Therefore, their presence is not considered as a drawback, but it has been considered as a probe to monitor QTM properties [6]. In a recent publication, we discussed the role played by the intermolecular interactions on the behavior of SMMs, mainly through a bibliographic point of view [7]. In this paper, a systematic presentation of the study of representative examples of SMMs is attempted in the light of the Hirshfeld surface (HS) analysis tools and what can be gained by using this valuable tool in studying the intermolecular interactions in crystals. The HS is calculated by considering the electron density and position of neighboring atoms inside and outside the surface and partitions the space into nonoverlapping volumes defined by a surface which surrounds each molecule [8]. Thus, the HS reflects, in considerable detail, the immediate 
environment of a molecule in a crystal. HSs decorated with various functions/properties present the sites where the intermolecular interactions are developed [9]. HS analysis tools meet the basic criterion [8], which a method must satisfy for studying intermolecular interactions in a crystal structure and to be the least biased possible, which was set by Desiraju in 1997 [10]: "To visualize a crystal structure in its entirety, not just look at selected intermolecular interactions that have been deemed to be important". HSs have been used extensively in the study of polymorphic organic materials [11], but recently they have also used in the study of transition metal complexes [12-14].

\section{Materials and Methods}

The HS studies of all complexes were performed by using the CrystalExplorer package V.17.5 [15]. In this study, the $d_{\text {norm }}$ decorated HSs are mainly discussed in relation to corresponding fingerprint plots. $d_{\text {norm }}$ is a normalized contact distance, defined in terms of $d_{\mathrm{e}}, d_{\mathrm{i}}$ and the Van der Waals (VdW) radii of two atoms at a distance $d_{\mathrm{e}}$ outside from a point on the surface and at a distance $d_{\mathrm{i}}$ inside the surface correspondingly (Spackman, 2009). It should be mentioned that the color scheme of a $d_{\text {norm }}$ decorated HS corresponds to the magnitude of intermolecular interactions ranging from strong (red color) to moderate (white) to weak (blue). The fingerprint plot is a 2D diagram derived from the HS and gives the frequency of occurrence of each combination of pairs $d_{\mathrm{e}}, d_{\mathrm{i}}$ on the surface, and each such combination is interpreted as some type of interaction. The points $d_{\mathrm{e}}>d_{\mathrm{i}}$ lie above the main diagonal of the plot and correspond to the donor atoms of the molecule, and points $d_{\mathrm{e}}<d_{\mathrm{i}}$, which lie below the main diagonal, correspond to the acceptor ones. $\pi \cdots \pi$ and $\mathrm{C}-\mathrm{H} \cdots \pi$ interactions result in easily recognizable patterns on the HSs decorated with the shape property [9]. Differences in the fingerprint plots among similar compounds are attributed to differences in the packing of molecules and give valuable information for their structures [16]. For the HS analysis studies, the CIF files of the corresponding compounds were used, which have been retrieved from Cambridge Structural Database (CSD) [17]. All the studied compounds are listed in Table 1 with the corresponding code name as it is stored in CSD [17].

Table 1. Studied compounds.

\begin{tabular}{ccc}
\hline Compound & CSD-Code & Reference \\
\hline $\mathbf{1}\left[\mathrm{Mn}_{4} \mathrm{O}_{3} \mathrm{Cl}_{4}\left(\mathrm{O}_{2} \mathrm{R}\right)_{3}(\mathrm{py})_{3}\right], \mathrm{R}=\mathrm{CH}_{2} \mathrm{CH}_{3}$ & KUCHIZ & {$[18]$} \\
$\mathbf{2}\left[\mathrm{Mn}_{4} \mathrm{O}_{3} \mathrm{Cl}_{4}\left(\mathrm{O}_{2} \mathrm{R}\right)_{3}(\mathrm{py})_{3}\right], \mathrm{R}=\mathrm{CH}_{3}$ & KUCHOF & {$[18]$} \\
$3\left[\mathrm{Fe}_{9} \mathrm{O}_{4}(\mathrm{OH})_{4}\left(\mathrm{O}_{2} \mathrm{CPh}\right)_{13}(\text { heenH })_{2}\right]$ & YUTZAP & {$[19]$} \\
$4\left[\mathrm{Mn}_{4}(\mathrm{Bet})_{4}(\mathrm{mdea})_{2}(\mathrm{mdeaH})_{2}\right]\left(\mathrm{BPh}_{4}\right)_{4}$, & UZUJAB & {$[20]$} \\
$5\left[\mathrm{Cu}(\mathrm{Pid})\left(\mathrm{OSO}_{3}\right)\left(\mathrm{H}_{2} \mathrm{O}\right)\right] \cdot\left(\mathrm{H}_{2} \mathrm{O}\right)$ & IPUJOT & {$[21]$} \\
\hline
\end{tabular}

\section{Results}

The importance of intermolecular interactions on the SMM properties were studied for the first time for the compounds $\left(\mathrm{Mn}_{4} \mathrm{O}_{3} \mathrm{Cl}_{4}\left(\mathrm{O}_{2} \mathrm{R}\right)_{3}(\mathrm{py})_{3}\right)$ where $\mathrm{R}=\mathrm{CH}_{2} \mathrm{CH}_{3}$, and $\mathrm{CH}_{3}$ corresponds to compounds $\mathbf{1}$ and 2, respectively [22]. For these systems, step-like features are observed in the hysteresis loops of magnetization versus applied field measurements, at $40 \mathrm{mK}$. The observed minor differences could be explained with an intradimer superexchange interaction $\mathrm{J}$ and an interdimer one $\mathrm{J}^{\prime}$, which is negligible in the case of compound $\mathbf{1}$ and is present in the case of $\mathbf{2}$. This model could also explain the absence of the quantum tunneling at zero field in both cases and the observation of fine structure features in the hysteresis loop of compound 2. Both interactions are antiferromagnetic and the intradimer one is stronger than the interdimer one. This phenomenon has been characterized as exchange-biased quantum tunneling [3] and has been considered to open new perspectives in the use of supramolecular chemistry to modulate the quantum physics of these molecular nanomagnets [3,22]. In Figures 1a and 2a, a dimer is presented for compounds 1 and 2, respectively, and the intradimer and the interdimer intermolecular interactions are clearly seen on the $d_{\text {norm }}$ decorated HS. The percentage contribution of 
the different type of interactions is as follows for the most important ones (compound 1, compound 2): $(33.5 \%, 25.9 \%)(\mathrm{H} \cdots \mathrm{H}),(17.4 \%, 18.3 \%)(\mathrm{Cl} \cdots \mathrm{H} / \mathrm{H} \cdots \mathrm{Cl}),(19.6 \%, 14.7 \%)$ $(\mathrm{C} \cdots \mathrm{H} / \mathrm{H} \cdots \mathrm{C}),(8.2 \%, 14.1 \%)(\mathrm{N} \cdots \mathrm{H} / \mathrm{H} \cdots \mathrm{N}),(11.8 \%, 11.9 \%)(\mathrm{O} \cdots \mathrm{H} / \mathrm{H} \cdots \mathrm{O})$. The shortest $\mathrm{Cl} \cdots \mathrm{H} / \mathrm{H} \cdots \mathrm{Cl}$ distances are about $2.75 \AA$ in the case of $\mathbf{1}$ and $2.9 \AA$ in the case of $\mathbf{2}$, which is less than the sum of $\mathrm{VdW}$ radius $2.95 \AA$ ( $1.2 \AA$ for $\mathrm{H}$ and $1.75 \AA$ for $\mathrm{Cl})$ in the first case, and close to this value in the second case; this is the reason that these contact points are clearly seen in the case of $\mathbf{1}$ (Figure 1a). The $\mathrm{Cl} \cdots \mathrm{Cl}$ contact points are longer in the case of $\mathbf{1}, 3.9 \AA$, and shorted in the case of 2, 3.5 $\AA$. Thus, in the latter case, these contact points, although faded, as they are close to the sum of VdW radius ( $3.5 \AA)$, are clearly seen in the latter case.

\section{$\left[\mathrm{Mn}_{4} \mathrm{O}_{3} \mathrm{Cl}_{4}\left(\mathrm{O}_{2} \mathrm{R}\right)_{3}(\mathrm{py})_{3}\right], \mathbf{R}=\mathrm{CH}_{2} \mathrm{CH}_{3}$}

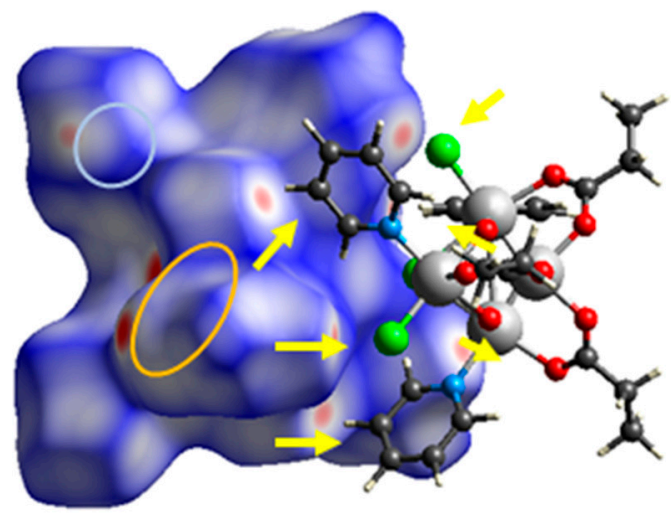

(a)
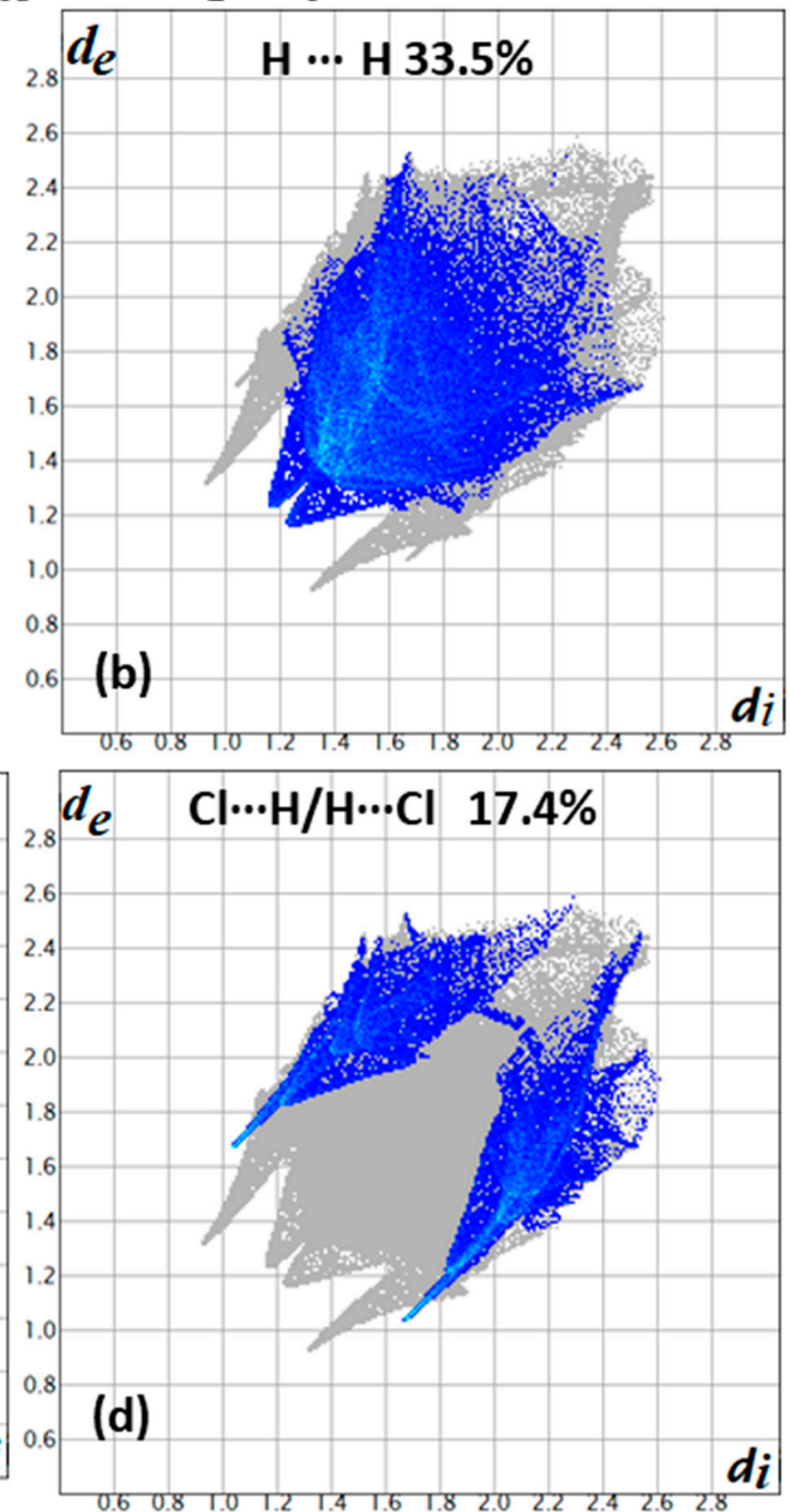

Figure 1. (a) A dimer of complexes with one molecule to be surrounded with a $d_{\text {norm }}$ decorated HS and the other in a ball and stick presentation for compound 1. The six orange vectors indicate the six contact points of $\mathrm{Cl} \cdots \mathrm{H}$ type of interactions. The red areas in the orange and cyan ellipses indicate $\mathrm{O} \cdots \mathrm{H}$ and $\mathrm{C} \cdots \mathrm{H}$ contact points. Contribution of each type of interactions (b) $\mathrm{H} \cdots \mathrm{H},(\mathbf{c}) \mathrm{O} \cdots \mathrm{H} / \mathrm{H} \cdots \mathrm{O}$, and (d) $\mathrm{Cl} \cdots \mathrm{H} / \mathrm{H} \cdots \mathrm{Cl}$ derived from the fingerprint plot of compound 1 . The outline of the full fingerprint contribution is shown in gray. 


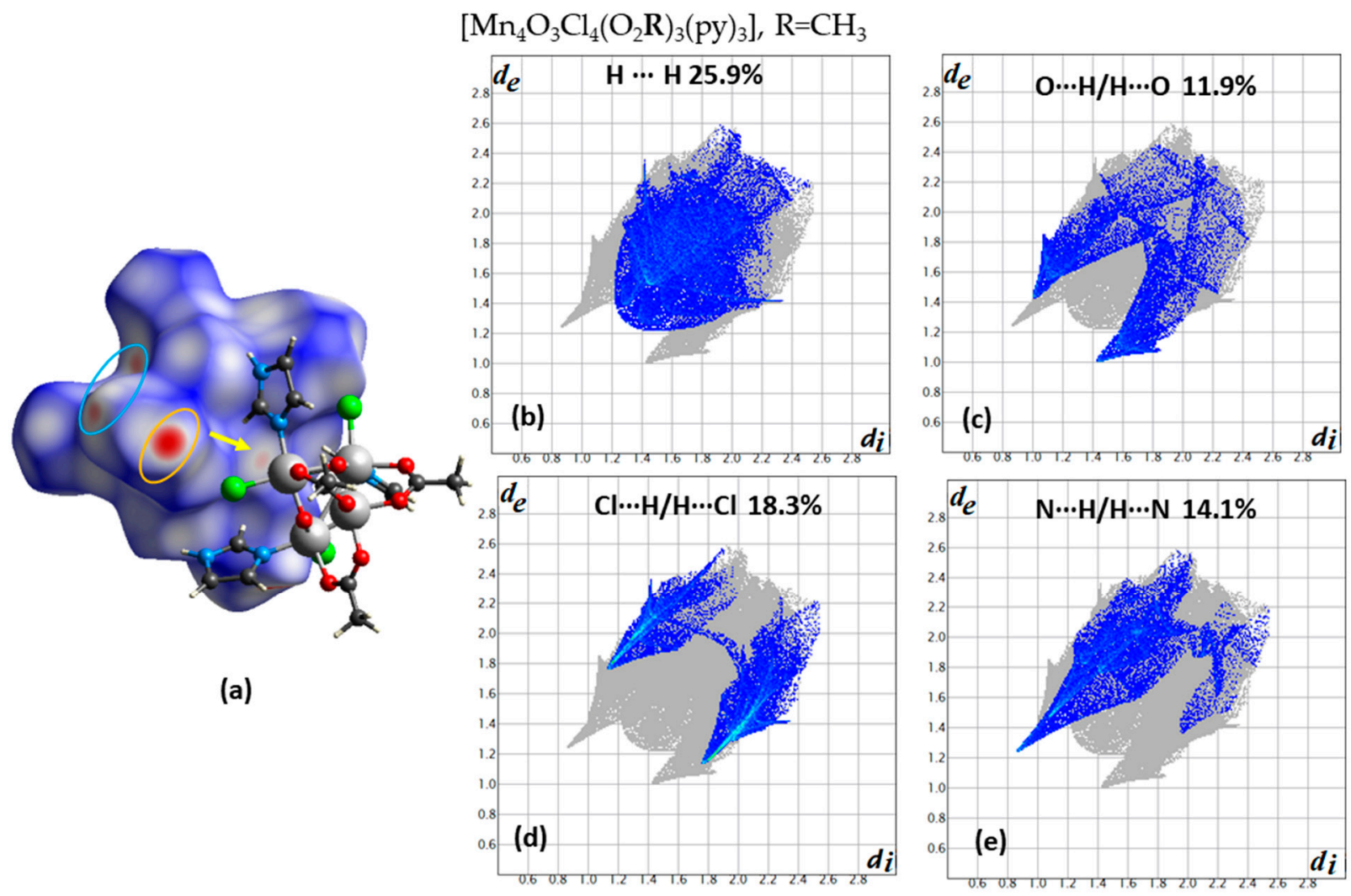

Figure 2. (a) A dimer of complexes with one molecule to be surrounded with a $d_{\text {norm }}$ decorated HS and the other in a ball and stick presentation for compound 2 . The orange vector in the middle indicates the $\mathrm{Cl} \cdots \mathrm{Cl}$ contact points. The red areas in the orange and cyan ellipses indicate $\mathrm{H} \cdots \mathrm{N}$ (only donor points are seen for this view) and $\mathrm{O} \cdots \mathrm{H} / \mathrm{H} \cdots \mathrm{O}$ contact points. Contribution of $(\mathbf{b}) \mathrm{H} \cdots \mathrm{H},(\mathbf{c}) \mathrm{O} \cdots \mathrm{H} / \mathrm{H} \cdots \mathrm{O}$, (d) $\mathrm{Cl} \cdots \mathrm{H} / \mathrm{H} \cdots \mathrm{Cl}$, and (e) $\mathrm{N} \cdots \mathrm{H} / \mathrm{H} \cdots \mathrm{N}$ interactions in the fingerprint plot diagram. The outline of the full fingerprint contribution is shown in gray.

There are lattice solvents in the structure of both compounds, but this characteristic is more clearly seen only in the fingerprint plot (Figure $2 b$ ) of compound 2, where the distribution of contact points is asymmetric with respect to the main diagonal in the fingerprint plot, and the contact points $\mathrm{H} \cdots \mathrm{N}$ are among the clusters and the acetonitrile solvents (Figure 2e). The $\mathrm{Cl} \cdots \mathrm{Cl}$ (with contribution of $0.3 \%$ for compound 1 and $0.5 \%$ for compound 2) and $\mathrm{Cl} \cdots \mathrm{H} / \mathrm{H} \cdots \mathrm{Cl}$ contact points have been considered as the paths of interactions that alter the characteristics of the hysteresis loops for both compounds $[3,22]$. Although both compounds crystallize in the same space group (R-3) and they have almost the same unit cell dimensions $\left(a=b=c=13.156 \AA\right.$ and $13.031 \AA, \alpha=\beta=\gamma=74.56(3)^{\circ}$ and $74.81(2)^{\circ}, V=2068.64 \AA^{3}$ and $2015.93 \AA^{3}$ for compound $\mathbf{1}$ and 2 , respectively), the packing of dimers are quite different as it is concluded for the differences observed in fingerprint plots of these compounds (Figures $1 \mathrm{~b}-\mathrm{d}$ and $2 \mathrm{~b}-\mathrm{e}$ ).

Another characteristic example is the dimers of clusters which are observed in the structure of $\left(\mathrm{Fe}_{9} \mathrm{O}_{4}(\mathrm{OH})_{4}\left(\mathrm{O}_{2} \mathrm{CPh}\right)_{13}(\text { heenH })_{2}\right)$ [19], where, in the hysteresis loop measurements below $1 \mathrm{~K}$, QTM steps are observed which are shifted relative to zero shift, but also a QTM step at zero field is observed, indicating a mixed state. This behavior has been interpreted as due to disorder of an oxygen atom on the heen $\mathrm{H}^{-}$ligand that occupies two sites with $36 / 64 \%$ occupancies, with $2 / 3(\sim 64 \%)$ contributing to the formation of dimers and the remaining $1 / 3$ does not, because they form an intramolecular hydrogen bond. Thus, the $2 / 3$ of them switches on the exchange-biased field and the rest switches it off. Based on Hirshfeld analysis (Figure 3a), only $2.4 \%$ of the interactions contribute to the hydrogen bond formation, which results in the formation of dimers, and the rest, according to the fingerprint plot (Figure $3 \mathrm{~b}$ ), are of $\mathrm{H} \cdots \mathrm{H}$ type (78.6\%) (a value which indicates 
that the dimers are almost isolated) and of $\mathrm{C}-\mathrm{H} \cdots \pi$ type $(16.8 \%)$, which contribute to the interdimer interactions, thus resulting in formation of the 3D architecture of the compound. The symmetric distribution of contact points in fingerprint plots indicates that one type of molecule exists in the unit cell (Figure $3 b-d)$.

(a)
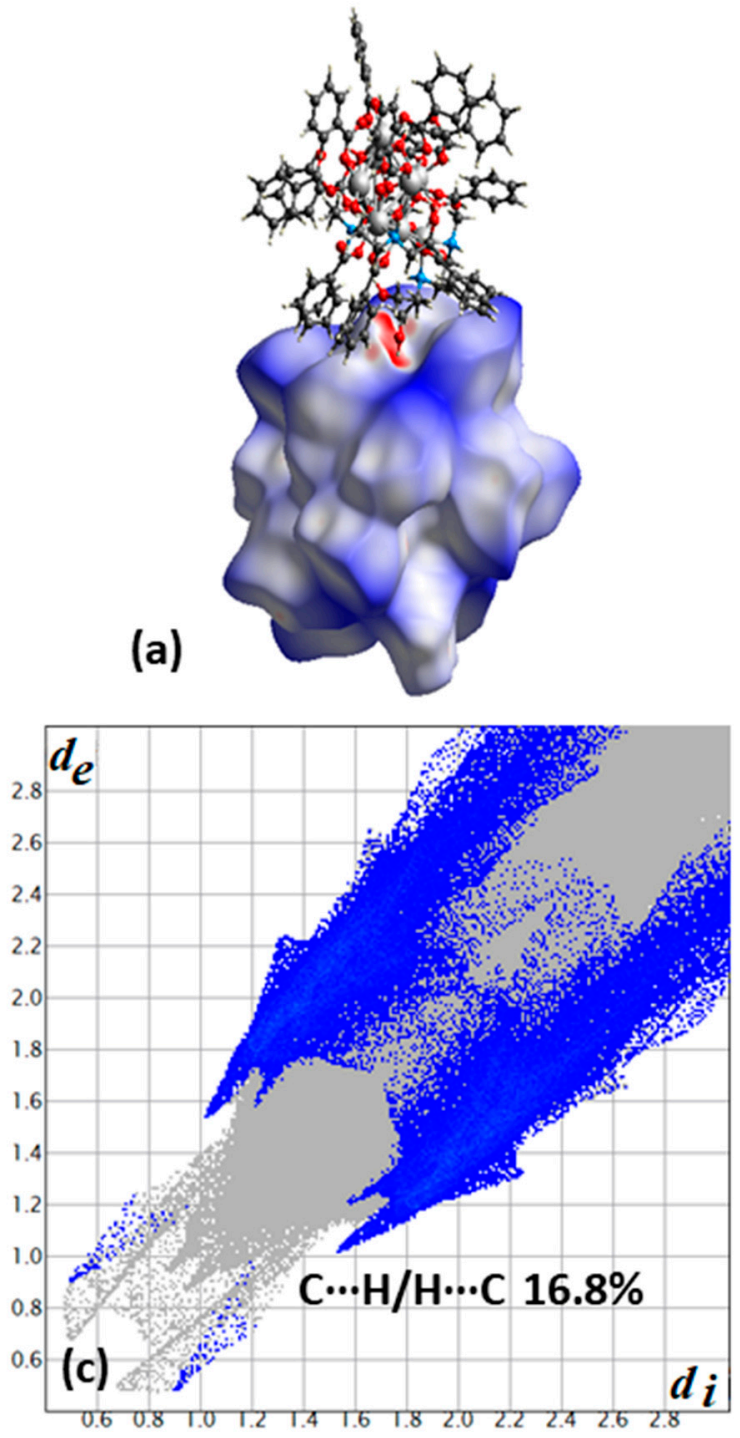
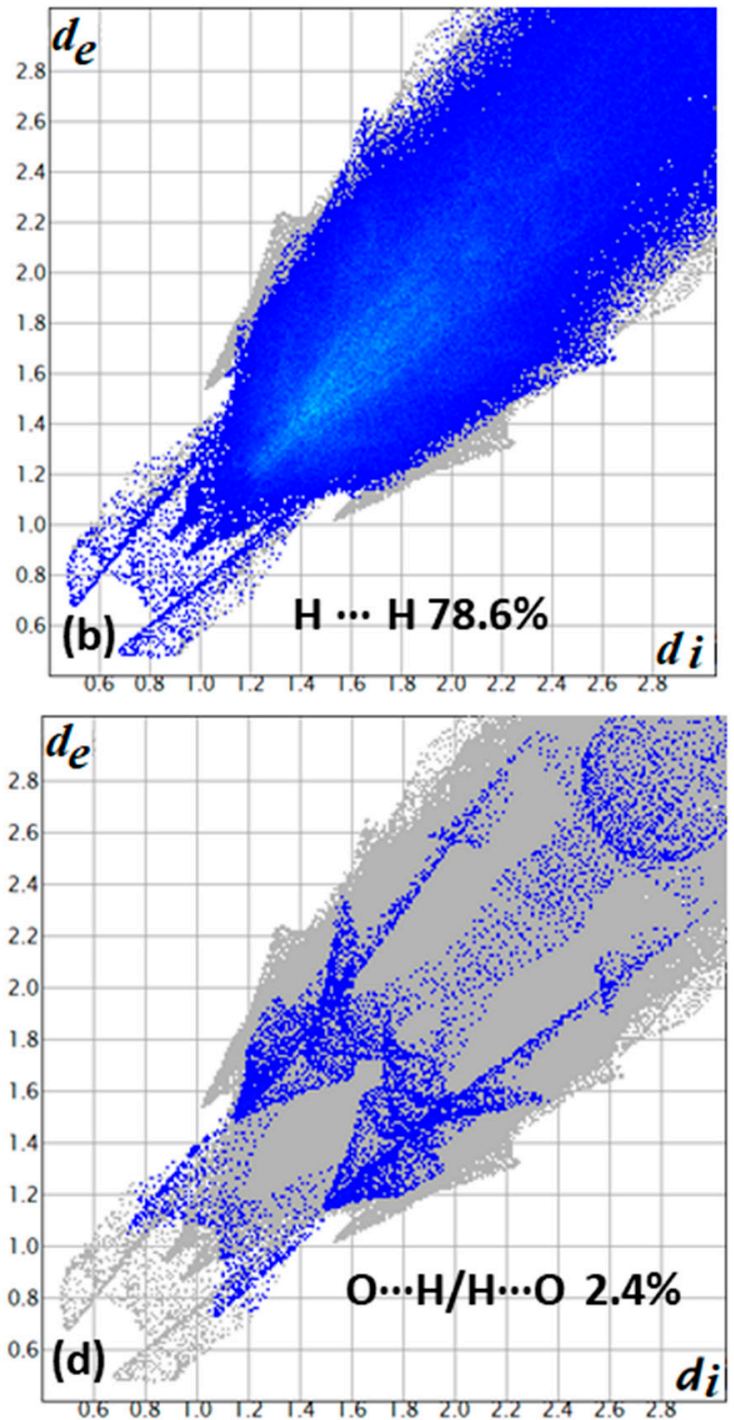

Figure 3. (a) A dimer of complexes with one molecule to be surrounded with a $d_{\text {norm }}$ decorated HS and the other in a ball and stick presentation for compound 3. Contribution of each type of interactions (b) $\mathrm{H} \cdots \mathrm{H}$, (c) $\mathrm{C} \cdots \mathrm{H} / \mathrm{H} \cdots \mathrm{C}$, and (d) $\mathrm{O} \cdots \mathrm{H} / \mathrm{H} \cdots \mathrm{O}$ derived from the fingerprint plot of compound 3 . The outline of the full fingerprint contribution is shown in gray.

In the light of these studies, compound 4 was synthesized, where the presence of $\mathrm{BPh}_{4}{ }^{-}$anions around the $\left(\mathrm{Mn}_{4}(\text { Bet })_{4}(\text { mdea })_{2}(\text { mdeaH })_{2}\right)^{+} \mathrm{SMM}$ cations and, in addition, the absence of solvents, make this system ideal for hysteresis loop measurements and EPR studies [20]. For the calculation of the $d_{\text {norm }}$ decorated HS (Figure 4a), only the SMM cation was used, and this is reflected in the distribution of contact points in the fingerprint plot (Figure $4 \mathrm{~b}$ ), where almost all the points are above the main diagonal of the plot, which means that the cation serves mostly as a donor. Both cation and anions contribute to $\mathrm{H} \cdots \mathrm{H}$ (73.6\%) type interactions, the cation serves as a donor for the C $\cdots \mathrm{H}(25.3 \%)$ type of contacts, as all the points for this type of interactions lie above the main diagonal, and as an acceptor for the $\mathrm{O} \cdots \mathrm{H}$ one $(1.1 \%)$, as all these contact points lie below the main diagonal. 


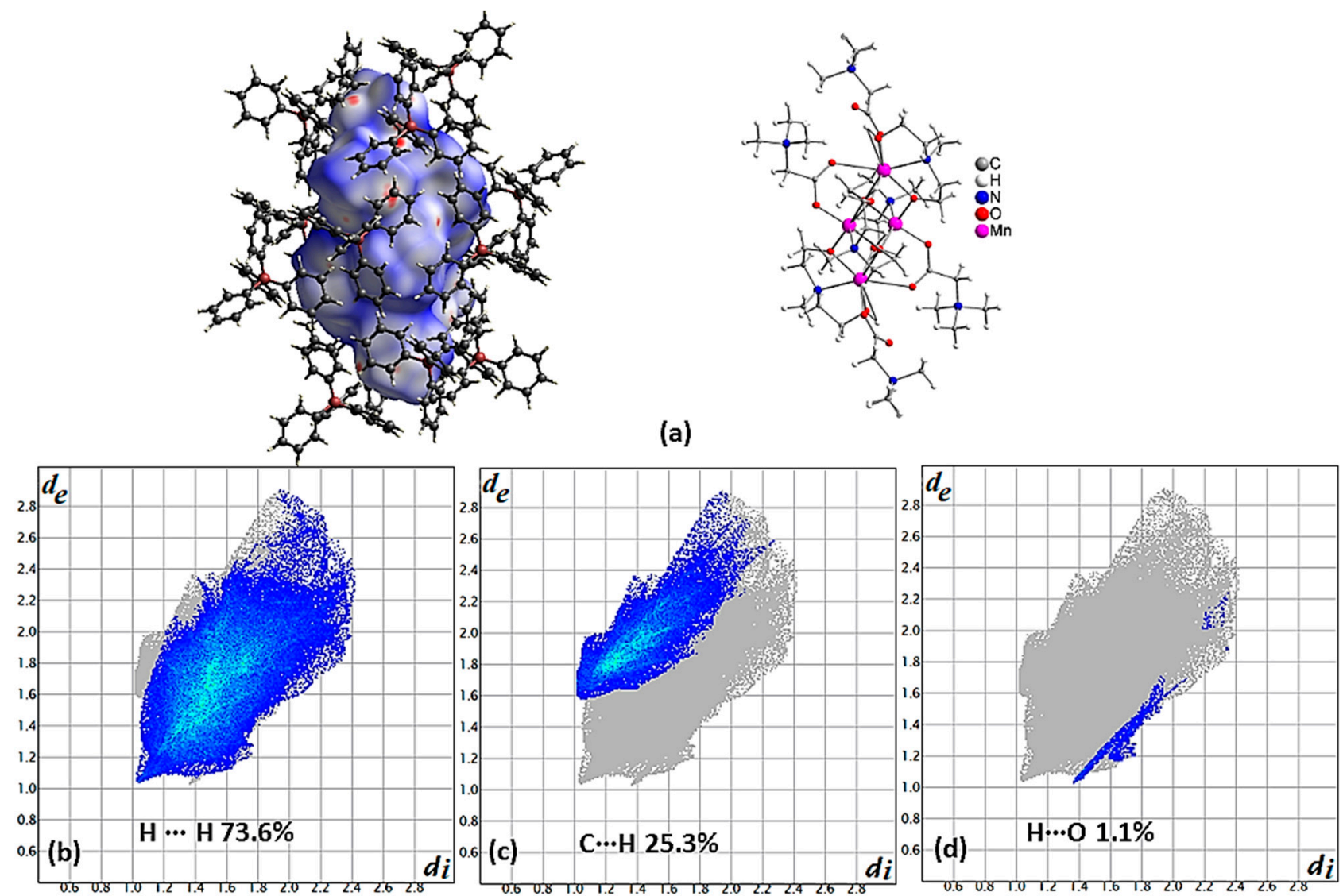

Figure 4. (a) The cation (Mn4(Bet)4(mdea)2(mdeaH)2) ${ }^{+}$is presented with a $d_{\text {norm }}$ decorated HS and the anions surrounding it in a ball and stick presentation for compound 4 (left). The cation is presented in ball and stick method to the right of the figure at the same orientation. Contribution of the most important type of interactions $(\mathbf{b}) \mathrm{H} \cdots \mathrm{H},(\mathbf{c}) \mathrm{C} \cdots \mathrm{H}$, and (d) $\mathrm{H} \cdots \mathrm{O}$ derived from the fingerprint plot of compound 4 . The outline of the full fingerprint contribution is shown in gray.

Structural intermolecular interactions, such as $\pi-\pi$ stacking, $\mathrm{C}-\mathrm{H} \cdots \mathrm{O}$, and $\mathrm{O}-\mathrm{H} \cdots \mathrm{O}$ hydrogen bonds, and diamagnetic metal cations have been considered as pathways for magnetic superexchange noncovalent interactions [23]. Special attention has been given to the $\pi \cdots \pi$ one [21,24]. For compound 5 [21], the contribution of $\mathrm{H} \cdots \mathrm{H}, \mathrm{O} \cdots \mathrm{H} / \mathrm{H} \cdots \mathrm{O}$, $\mathrm{C} \cdots \mathrm{C}$, and $\mathrm{C} \cdots \mathrm{H} / \mathrm{H} \cdots \mathrm{C}$ is $39.8,38.1,8.3$, and $7.3 \%$, respectively (Figure $5 \mathrm{~b}-\mathrm{d}$ for the first three type of intermolecular interactions). Theoretical calculations show that in both superexchange interactions through $\mathrm{O} \cdots \mathrm{H} / \mathrm{H} \cdots \mathrm{O}$ (hydrogen bonds), $\mathrm{C} \cdots \mathrm{C}(\pi \cdots \pi$ type) are antiferromagnetic, with the second to be stronger. The $\pi \cdots \pi$ type of interaction are clearly seen on the shape decorated HSs where the characteristic blue and red triangles are present (Figure 5a).

Table 2 lists parameters for the most important magnetic properties of all the compounds studied in this work, together with the characteristic patterns observed on the HSs. 

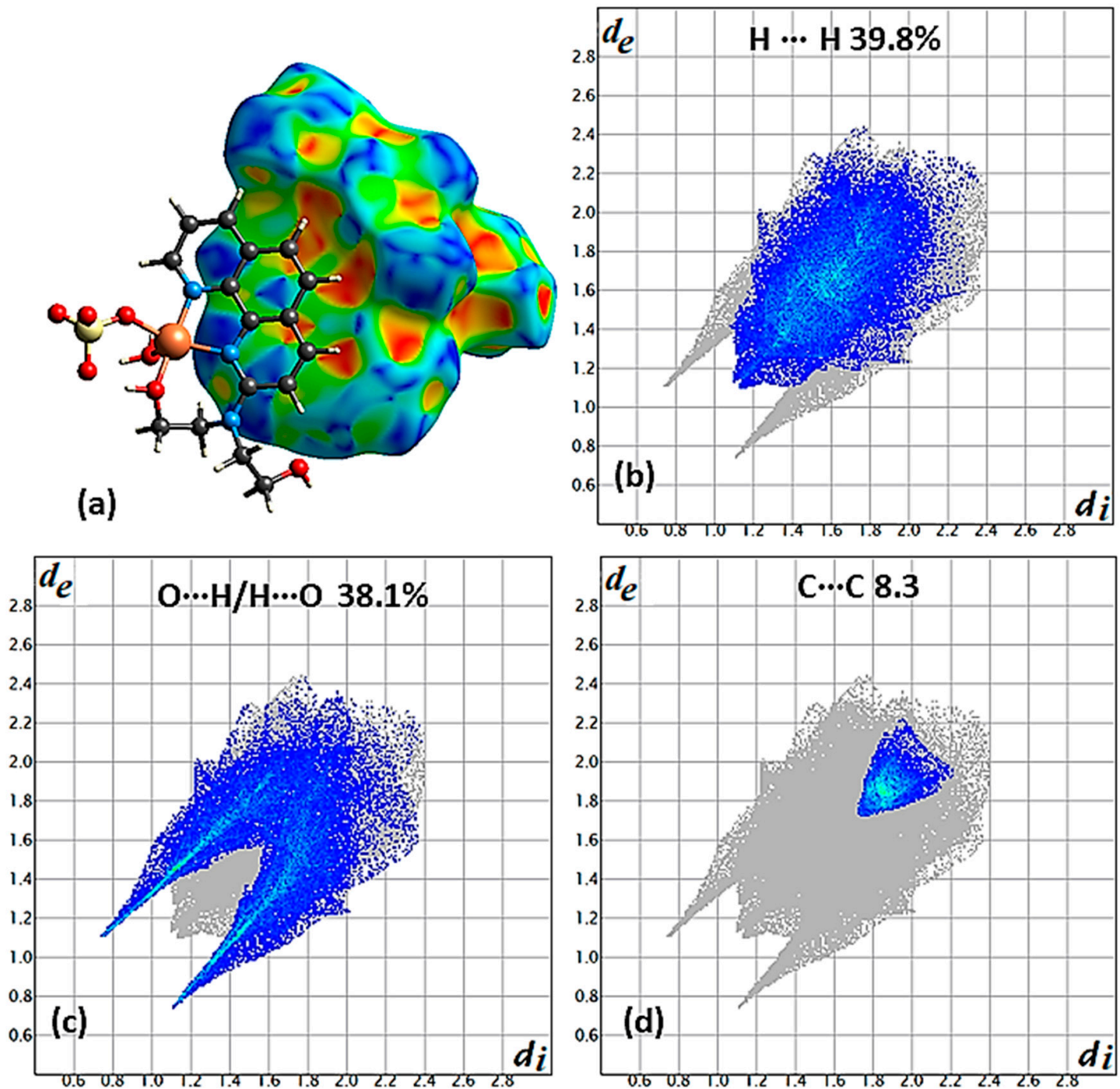

Figure 5. (a) A dimer of complexes presenting $\pi \cdots \pi$ type of intermolecular interactions with one molecule to be surrounded with a shape decorated HS and the other in a ball and stick presentation for compound 5. Contribution of the most interesting types of interactions, (b) $\mathrm{H} \cdots \mathrm{H},(\mathbf{c}) \mathrm{C} \cdots \mathrm{H} / \mathrm{H} \cdots \mathrm{C}$, and (d) $\mathrm{O} \cdots \mathrm{H} / \mathrm{H} \cdots \mathrm{O}$ derived from the fingerprint plot of compound 5 . The outline of the full fingerprint contribution is shown in gray.

Table 2. Physical parameters and patterns on HSs of the studied compound.

\begin{tabular}{|c|c|c|c|c|c|}
\hline Compound & 1 & 2 & 3 & 4 & 5 \\
\hline $\begin{array}{c}S \\
\text { (spin of } \\
\text { ground state) }\end{array}$ & $9 / 2$ & $9 / 2$ & $7 / 2$ & 9 & $1 / 2$ \\
\hline SMM & $\begin{array}{c}\text { Yes } \\
\text { biased QTM } \\
\text { hysteresis loop }\end{array}$ & $\begin{array}{c}\text { Yes } \\
\text { biased QTM } \\
\text { hysteresis loop }\end{array}$ & $\begin{array}{c}\text { Yes } \\
\text { biased QTM } \\
\text { hysteresis loop }\end{array}$ & $\begin{array}{c}\text { Yes } \\
\text { QTM } \\
\text { hysteresis loop }\end{array}$ & No \\
\hline$\tau_{\mathrm{o}}(\mathrm{s})$ & $1.17 \times 10^{-8}$ & $1.17 \times 10^{-8}$ & $6.0 \times 10^{-10}$ & $2.5 \times 10^{-8}$ & - \\
\hline$U_{\text {eff }}\left(\mathrm{cm}^{-1}\right)$ & 13 & 13 & 5.3 & 14.2 & - \\
\hline $\begin{array}{l}\text { Intradimer } \\
\text { interactions }\end{array}$ & antiferromagnetic & antiferromagnetic & antiferromagnetic & - & antiferromagnetic \\
\hline Patterns on HS & $\begin{array}{c}\text { Red spots on } \mathrm{d}_{\text {norm }} \\
\mathrm{HS} \\
\mathrm{Cl} \cdots \mathrm{H}, \mathrm{O} \cdots \mathrm{H} \\
\mathrm{C} \cdots \mathrm{H}\end{array}$ & $\begin{array}{c}\text { Red spots on } \mathrm{d}_{\text {norm }} \\
\mathrm{HS} \\
\mathrm{N} \cdots \mathrm{H}, \mathrm{O} \cdots \mathrm{H} \\
\mathrm{Cl} \cdots \mathrm{Cl}\end{array}$ & $\begin{array}{c}\text { Red spots on } \mathrm{d}_{\text {norm }} \\
\mathrm{HS} \\
\mathrm{O} \cdots \mathrm{H}\end{array}$ & $\begin{array}{l}\text { Red spots on } d_{n o r m} \\
\text { O } \cdots H\end{array}$ & $\begin{array}{l}\text { Blue and red } \\
\text { triangles on } \\
\text { Shape HS }\end{array}$ \\
\hline reference & [25] & [25] & [19] & [20] & [21] \\
\hline
\end{tabular}




\section{Conclusions}

The study of intermolecular interactions of SMM compounds with the HS tools could help to identify special characteristics in their structures which, in turn, could help to easier interpret and understand their physical properties, which are related to their structures. Special patterns on the decorated HSs or in the fingerprint plots are related to packing characteristics, which are indicative of the presence or absence of other molecules in the structure, as their presence is reflected on the surface or on the fingerprint plots. It proves to be helpful in the comparison of structures with common characteristics. Finally, as all the interactions are identified, it gives a complete overview of all types of interactions and helps to estimate the role played by each one of them in structure formation, and the relation of specific characteristics of the structure with the properties of the studied compound.

Author Contributions: Conceptualization, V.P. and C.P.R.; methodology, V.P. and D.D.; software, V.P. and D.D.; validation, V.P. and C.P.R.; writing-original draft preparation, V.P.; writing-review and editing, V.P., C.P.R. and D.D.; supervision, V.P. and C.P.R.; project administration, V.P. All authors have read and agreed to the published version of the manuscript.

Funding: Dr. V. Psycharis would like to thanks the Special Account of NCSR "Demokritos" for financial support concerning the operation of the X-ray facilities at INN through the internal program enti-tled "Structural study and characterization of polycrystalline materials" (NCSR Demokritos, ELKE \#10813).

Conflicts of Interest: The authors declare no conflict of interest.

\section{References}

1. Christou:, G. Single Molecule Magnets: A molecular approach to nanoscale magnetic materials. Polyhedron 2005, 24, 2065. [CrossRef]

2. Bogani, L.; Wernsdorfer, W. Molecular spintronics using single-molecule magnets. Nat. Mater. 2008, 7, 179-186. [CrossRef]

3. Wernsdorfer, W.; Aliaga-Alcalde, N.; Hendrickson, D.N.; Christou, G. Exchange-biased quantum tunneling in a supramolecular dimer of single-molecule magnets. Nature 2002, 416, 406. [CrossRef]

4. Thomas, L.; Lionti, F.; Balou, R.; Gatteschi, D.; Sessoli, R.; Barbara, B. Macroscopic quantum tunneling of magnetization in a single crystal of nanomagnets. Nature 1996, 383, 145. [CrossRef]

5. Gatteschi, D.; Sessoli, R. Quantum Tunneling of Magnetization and Related Phenomena in Molecular Materials. Angew. Chem. Int. Ed. 2003, 42, 1521. [CrossRef] [PubMed]

6. Boskovic, C.; Bircher, R.; Tregenna-Piggott, P.L.W.; Gu del, H.U.; Paulsen, C.; Wernsdorfer, W.; Barra, A.L.; Khatsko, E.; Neels, A.; Stoeckli-Evans, H. Ferromagnetic and Antiferromagnetic Intermolecular Interactions in a New Family of Mn4 Complexes with an Energy Barrier to Magnetization Reversal. J. Am. Chem. Soc. 2003, 125, 14046-14058. [CrossRef]

7. Pissas, M.; Psycharis, V.; Raptopoulou, C.P.; Sanakis, Y. Unique Magnetic Properties. In Single-Molecule Magnets. Molecular Architectures and Building Blocks for Spintronics, 1st ed.; Holynska, M., Ed.; Wiley-VCH Verlag GmbH \& Co.: Weinheim, Germany, 2019; pp. 41-86.

8. Spackman, M.A.; Jayatilaka, D. Hirshfeld Surface Analysis. CrystEngComm 2009, 11, 19-32. [CrossRef]

9. McKinnon, J.J.; Spackman, M.A.; Mitchell, A.S. Novel tools for visualizing and exploring intermol ecular interactions in molecular crystals. Acta Crystallogr. 2004, B60, 627-668. [CrossRef]

10. Desiraju, G.R. Designer crystals: Intermolecular interactions, network structures and supramolecular synthons. Chem. Commun. 1997, 1475-1482. [CrossRef]

11. McKinnon, J.J.; Fabbiani, F.P.A.; Spackman, M.A. Comparison of Polymorphic Molecular Crystal Structures through Hirshfeld Surface Analysis. Cryst. Growth Des. 2007, 7, 755-769. [CrossRef]

12. Boubakri, R.; Szybowicz, M.; Sadej, M.; Soudani, S.; Lefebvre, F.; Ferretti, V.; Nasr, C.B.; Kaabi, K. Synthesis, Single Crystal Structural Investigation, Hirshfeld Surface Analysis, Thermoanalysis and Spectroscopic Study of Two New Cu(II) and Co(II) Transition-Metal Complexes. Crystals 2021, 11, 986. [CrossRef]

13. Kang, Q.-P.; Li, X.-Y.; Wang, L.; Zhang, Y.; Dong, W.-K. Containing-PMBP N2O2-donors transition metal(II) complexes: Synthesis, crystal structure, Hirshfeld surface analyses and fluorescence properties. Appl. Organometalic Chem. 2019, 42, $268-297$.

14. Villa-Pérez, C.; Ortega, I.C.; Vélez-Macías, A.; Payán, A.M.; Echeverría, G.A.; Sori, D.B.; Valencia-Uribe, G.C. Crystal Structure, Physicochemical Properties, Hirshfeld Surfaces Analysis and Antibacterial Activity Assays of Transition Metal Complexes of 6-Methoxyquinoline. New J. Chem. 2018, 42, 7166-7176. [CrossRef]

15. Spackman, P.R.; Turner, M.J.; McKinnon, J.J.; Wolff, S.K.; Grimwood, D.J.; Jayatilaka, D.; Spackman, M.A. CrystalExplorer: A program for Hirshfeld surface analysis, visualization and quantitative analysis of molecular crystals. J. Appl. Crystallogr. 2021, 54, 1006-1011. [CrossRef] [PubMed] 
16. Adam, D.; Martin, A.D.; Britton, J.; Easun, T.L.; Blake, A.J.; Lewis, W.; Schröder, M. Hirshfeld Surface Investigation of StructureDirecting Interactions within Dipicolinic Acid Derivatives. Cryst. Growth Des. 2015, 15, 1697-1706.

17. Allen, F.H. The Cambridge Structural Database: A quarter of a million crystal structures and rising. Acta Crystallogr. 2002, B52, 380. [CrossRef]

18. Hendrickson, D.N.; Christou, G.; Schmitt, E.A.; Libby, E.; Bashkin, J.S.; Wang, S.; Tsai, H.L.; Vincent, J.B.; Boyd, P.D.W.; Huffman, J.C.; et al. Photosynthetic Water Oxidation Center: Spin Frustration in Distorted Cubane MnIVMniii3 Model Complexes. J. Am. Chem. Soc. 1992, 114, 2455-2471. [CrossRef]

19. Bagai, R.; Wernsdorfer, W.; Abboud, A.K.; Christou, G. Exchange-Biased Dimers of Single-Molecule Magnets in OFF and ON States. J. AM. Chem. SOC. 2007, 129, 12918-12919. [CrossRef] [PubMed]

20. Heroux, K.J.; Quddusi, H.M.; Liu, J.; O’Brien, J.R.; Nakano, M.; Barco, E.D.; Hill, S.; Hendrickson, D.N. Cationic Mn4 SingleMolecule Magnet with a Sterically Isolated Core. Inorg. Chem. 2011, 50, 7367-7369. [CrossRef]

21. Li, H.; Zhang, S.-G.; Xie, L.-M.; Yu, L.; Shi, J.-M. $\pi-\pi$ Stacking, hydrogen bonding and anti-ferromagnetic coupling mechanism on a mononuclear $\mathrm{Cu}$ (II) complex. J. Coord. Chem. 2011, 64, 1456-1468. [CrossRef]

22. Tiron, R.; Wernsdorfer, W.; Aliaga-Alcalde, N.; Christou, G. Quantum tunneling in a three-dimensional network of exchangecoupled single-molecule magnets. Phys. Rev. B 2003, 68, 140407. [CrossRef]

23. Herchel, R.; Nemec, I.; Machata, M.; Travnícek, Z. Experimental and Theoretical Investigations of Magnetic Exchange Pathways in Structurally Diverse Iron(III) Schiff-Base Complexes. Inorg. Chem. 2015, 54, 8625-8638. [CrossRef] [PubMed]

24. Li, H.; Zhang, S.-G.; Xie, L.-M.; Yu, L.; Shi, J.-M. $\pi-\pi$ Stacking and magnetic coupling mechanism on a mononuclear Cu(II) complex. J. Coord. Chem. 2011, 64, 3595-3608. [CrossRef]

25. Aubin, D.M.J.; Wemple, M.W.; Adams, D.M.; Tsai, H.-L.; Christou, G.; Hendrickson, D.N. Distorted MnIVMnIII3 Cubane Complexes as Single-Molecule Magnets. J. Am. Chem. Soc. 1996, 118, 7746-7754. [CrossRef] 